\title{
Research on Value Co-creation and Empowerment of Knowledge-paid Platform Enterprises - DeDao APP as an Example
}

\begin{abstract}
Chen Guo ${ }^{1}$
${ }^{1}$ International Economics and Trade, Chongqing Technology and Business University, Chongqing, 400067, China Email:guofl1871@gmail.com

ABSTRACT

With the development of Internet economy, knowledge-paid platform enterprises constantly innovate their own business models to meet their development requirements. This paper mainly focuses on the innovation of business model based on the theory of value co-creation and enterprise "empowerment". We adopt the research method of "single case" to DeDao APP as the case object. This paper attempts to reveal that there is an obvious business model of combining value co-creation with enterprise "empowerment" between knowledge-paid platform enterprises and other market players. These two processes of value creation and enterprise "empowerment" are a whole process that interacts with each other and forms a driving force for enterprise development. The new business model of value creation combined with enterprise "empowerment" disclosed in this paper can provide certain reference for other platform enterprises to a certain extent.
\end{abstract}

Keywords: platform enterprise, Value co-creation, Enterprise "empowerment"

\section{INTRODUCTION}

With the rapid development of internet industry, various kinds of innovations emerge one after another. In addition to learning from or copying foreign experiences, new products and business models are being created to meet China's situation and needs. Internet knowledge payment (knowledge-paid) is one of them. ${ }^{[1]}$ In short, knowledge-paid refers to a business form that uses platforms and Internet tools to transform knowledge into products or services, and obtains corresponding benefits from meeting users' learning needs.

2016 is regarded as the "chances" of knowledge payment industry. The growth rate of knowledge -paid users in China is $100 \%$ in 2016, and it is estimated that the growth rate of knowledge-paid users in China will be $17.4 \%$ by $2021 .^{[2]}$

Under the background of vigorous development of platform economy, the value creation of various types of knowledge-paid enterprises is no longer a static onedimensional process dominated by traditional enterprises, but a dynamic multi-dimensional process of value creation, and it is also the change of organizational model from "empowerment" of traditional enterprises to "empowerment" of platform enterprises. The transformation of enterprises forms new value creation mode and strategic behavior, which will inevitably lead to the reconstruction of enterprise value chain system. ${ }^{[3]}$

This paper mainly discusses the innovation of business model of knowledge-based platform enterprises under this background.

As an important part of platform economy, the development and existing problems of knowledge-paid enterprises have been highly concerned by the business and academic circles. The competition in the future is no longer a dispute over technology or products, but a dispute over business models, so that the innovation of business models can break through the obstacles of development. ${ }^{[4]}$

The author tries to reveal through "single case" analysis that there is an obvious business model combining value co-creation and enterprise "empowerment" between knowledge-paid platform enterprises and other market players, and the two processes of value co-creation and enterprise "empowerment" are an overall process that interacts with each other and forms a driving force for enterprise 
development, but it should be noted that value cocreation is a two-way process between knowledge-paid platform enterprises and other market players. Besides, there is value co-creation among market players other than knowledge-paid platform enterprises, but enterprise "empowerment" is a one-way process and only exists between knowledge-paid platform enterprises and other market players. This theoretical model, which combines value co-creation with enterprise "empowerment" theory, is relatively rare in my limited cognition.

Therefore, this new business model, which combines value co-creation with enterprise "empowerment", provides a new transformation and development idea for other platform enterprises, and promotes the transformation of the traditional business model, thus adapting to the development of the digital economy era.

\section{LITERATURE REVIEW AND THEORETICAL BASIS}

\subsection{The core of value co-creation theory}

Value Co-creation refers to the value creation process in which consumers, producers, retailers or other consumers participate in products, services and experiences serving consumers. In essence, it is a value proposition and participation behavior that emphasizes experience-oriented and pays attention to the interaction between consumers and enterprises. ${ }^{[5]}$

The value co-creation theory abandons the traditional viewpoint that "enterprises create value for customers", and advocates that customers and enterprises actively create and re-create value. There are two important viewpoints in the development of value co-creation theory. First, Ramaswamy and Prahalad put forward the "value creation theory based on consumer experience", ${ }^{[6]}$ and second, Vargo and Lusch put forward the "value creation theory based on service-oriented logic". ${ }^{[7]}$

Ramaswamy and Prahalad believe that there is a great difference between the concept of value creation and "customer-oriented". ${ }^{[8]}$ The traditional business idea holds that "the customer is the God of the enterprise and is always right", and value co-creation is not only to please the customer unilaterally, nor to provide a large number of quality services to the customer blindly, nor to regard the customer as a product manager. Instead, enterprises and customers create an experience together in the interaction between the two sides. In this case, products and services become the carrier of experience, while value refers to experience value. In fact, in the process of value creation, consumers actively participate in and engage in dialogue with enterprises, so as to jointly construct differentiated products and service experiences, so as to adapt to consumers' personal background.

Vargo and Lusch believe that enterprises and customers create value together in the interaction of resource integration and capability application, which is not exchange value, but use value experienced in the process of consumption. ${ }^{[9]}$ in the service-oriented logic, people emphasize that service is the fundamental attribute of all economic exchanges. That is to say, what an enterprise provides on the surface is a tangible product, but in essence it is a service or solution. ${ }^{[10]}$ because the enterprise is the provider of value proposition and the customer is the judge of value in service interaction, the customer is the main body of value creation.

Generally speaking, there is a process of value creation based on experience and service between knowledge-paid platform enterprises and other market players, and knowledge-paid platform enterprises provide different value contents for other market players through different carriers; In turn, other market players also provide different value contents for knowledge-paid platform enterprises through different carriers. Besides, there may be a certain degree of value provision among market entities except knowledge-paid platform enterprises. As shown in the value co-creation model in Figure 1, the arrow indicates the direction of value provision. It is worth noting that the market subject is not limited to three, and there is not necessarily value provision between market subjects except knowledgepaid platform enterprises, which should be determined according to the enterprise's own situation. These three aspects of value supply make it possible to create value between knowledge platform and other market entities. This value co-creation also benefits all market players.

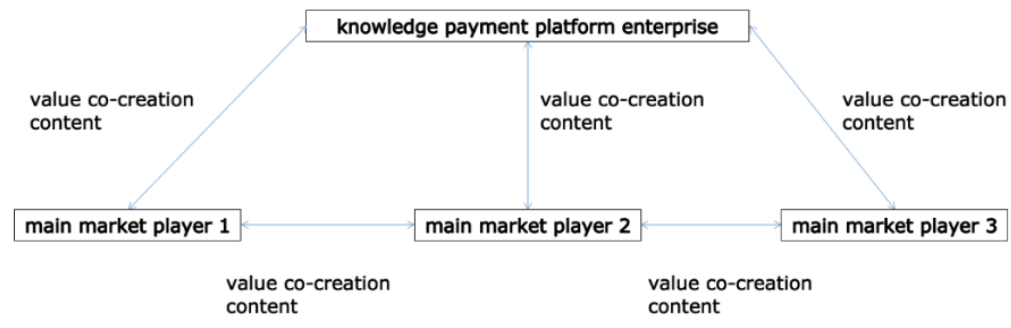

Figure 1.value co-creation model

Source: drawn by the author 


\subsection{From "empowerment" to "empowerment"}

The concept of "empowerment" is an extension of the traditional concept of enterprise "authorization". "Empowerment and authorization" emphasizes the distribution of rights within an organization, that is, through the establishment of an employee authorization mechanism, it realizes the "empowerment and promotion" of organizational groups. ${ }^{[11]}$ The rise of the concept of "empowerment" can be traced back to Haier's business model ${ }^{[12]}$ of "one person in one", "enterprise platformization and employee entrepreneurship". Then came the "group system", ${ }^{[13]}$ which was the basis for the prosperity of Handu Yishe. In these enterprise "empowerment" cases, it can be seen that their business models all revolve around "decentralization", namely, "amoeba"[14] proposed by inamori kazuo, which can more easily empower various resources to front-end enterprises and employees. While studying workers' action ability, Sun Zhongwei thought that although both English words of "empowerment" and "empowerment" correspond to "empowerment", the latter emphasizes the empowerment of action ability. ${ }^{[15]}$
Unlike the above-mentioned Acar and Puntoni, who only emphasize the "empowerment" within the organization, they believe that with the promotion of customers' trading status in the Internet era, enterprises are urged to have a quick, open and continuous dialogue with customers. ${ }^{[16]}$ Therefore, on the basis of traditional employee empowerment, a new perspective of customer empowerment is gradually derived, and it is advocated that enterprises should establish a good interactive relationship with customers by giving customers more initiative ${ }^{[17]}$ to maximize the interests of both parties. ${ }^{[18]}$

Generally speaking, the knowledge-paid platform enterprises can "empower" the other markets with different objects through the platform itself, so as to make the market subjects except the knowledge-paid enterprises show the enthusiasm of using the platform, and enhance its stickiness to the platform.Through this "empowering" knowledge payment platform, enterprises expand their influence scope and establish a more stable brand image.This process is shown in Figure 2 of the enterprise "empowerment" model, and the arrow direction indicates the enabling direction. It is worth noting that this direction is one-way, and there is no "empowerment" between market entities other than knowledge payment platform enterprises, and there are not limited to three market entities.

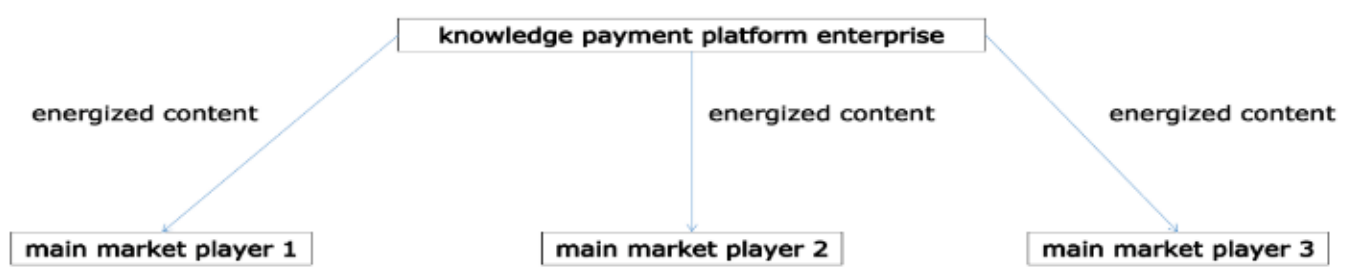

Figure 2. Enterprise "empowerment" model Source: drawn by the author

Combined with the theory of value co-creation and enterprise" empowerment" , we can find that there is an obvious process of the combination of value co creation and enterprise empowerment between the platform enterprises and other market players.As shown in Figure 3 , value co-creation and enterprise "empowerment" model, the two-way arrow provides the direction for value, and the one-way arrow provides the direction for the enterprise's "empowerment". The market entities are still not limited to three. It is worth noting that the two processes of value co-creation and enterprise "empowerment" have no sequence, and are an overall process that interacts and forms a driving force for the development of enterprises.

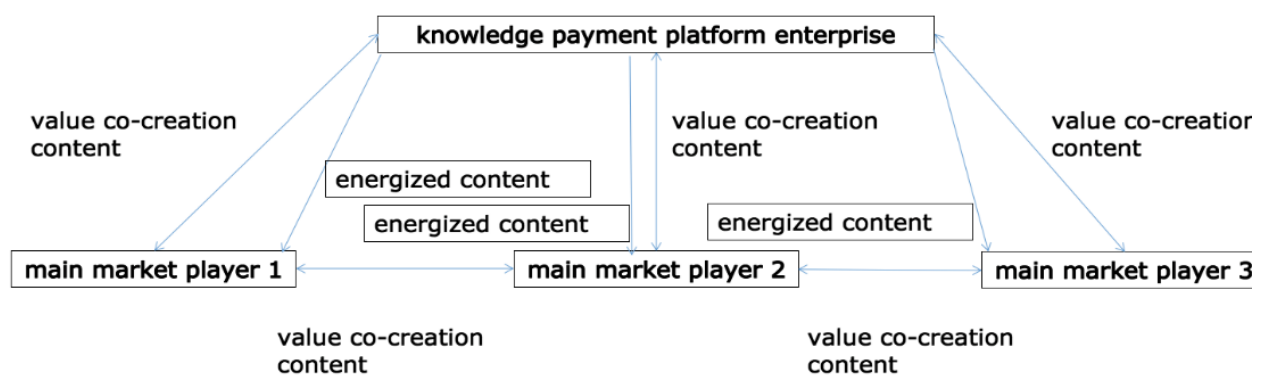

Figure 3.value co-creation and enterprise "empowerment" model

Source: drawn by the author 


\section{CASE DESCRIPTION}

The DeDao app is a knowledge service app produced by Logic Show team, which gathers the top quality resources in China. It is mainly aimed at lifelong learning users. It mainly uses high concentration knowledge of learning system by using fragmented time, and serves users with high-quality content such as paid columns, excellent courses, master classes and listening to this book every day, so as to enable users to complete systematic knowledge learning.

\subsection{DeDao APP development history}

2015:published;

2016:more than 3.5million users, annual revenue reached 100 million;

\section{7:}

1.Launch No.001 knowledge conference,launch 12 kinds of knowledge products, and share with peers in the industry;

2.Launch No.002 knowledge conference,focus on recommending daily reading column VIP;

3.More than 12 million users, daily average number of active users close to 900000 ;

\section{8:}

1.Strategy of opening Master Course;

2.Launch children's edition and get involved in children's education;
4.More than 20 million users;

2019: New upgrade of e-book products.

\subsection{Services provided by app}

The app mainly provides digital audio courses (with corresponding pictures and texts) and e-books; mainly through inviting experts, scholars and leading figures in various fields to settle in the platform; recording multiple audio courses in related fields to provide knowledge services to the public and realize knowledge realization, which is a typical PGC mode.

\section{CASE DISCUSSION}

In the business model of getting the app platform, the three main participants jointly create and share a variety of different values, and at the same time, DeDao app to "empower" the three.

Figure 4 shows the form of DeDao APP value cocreation and enterprise empowerment, which shows two aspects of content displayed on the app: one is value creation content and value creation carrier, in which "content" refers to what value participants obtain from other participants' resources, and "carrier" refers to the form of obtaining value,Among them, the solid line arrow indicates that the value interaction between the participants is direct, and the arrow direction indicates the value providing direction; the second is the enterprise "empowerment", which includes the object, type and content of empowerment.The arrow direction indicates the enabling direction.

3.The first "Friends of time"New Year speech held;

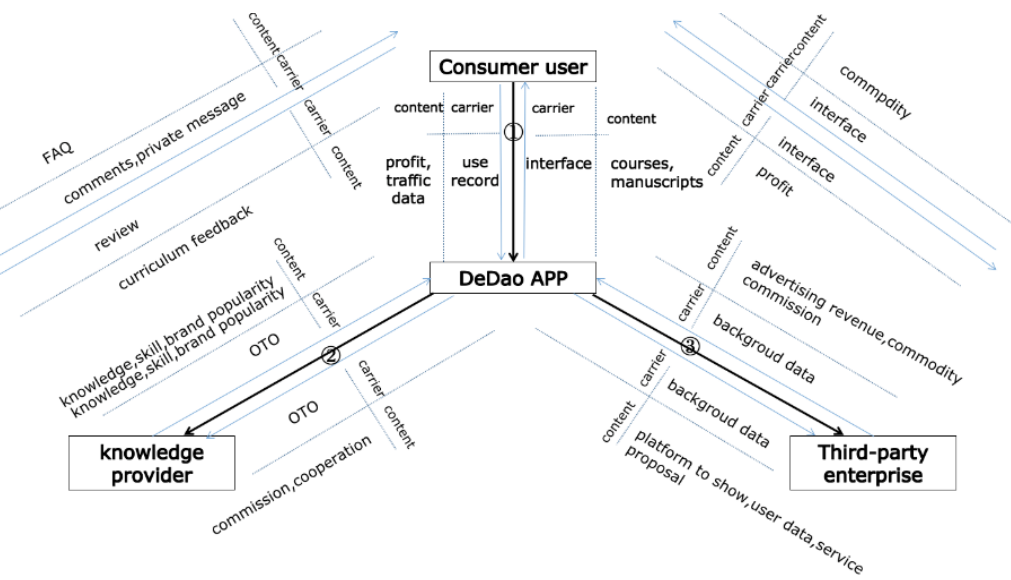

Notes:(1)Empowerment type: consumer Empowerment ,Empowerment project: consumer user,Empowerment content: build knowledge community, participating in social communication;(2)Empowerment type: base Empowerment, Empowerment project: ordinary knowledge provider,Empowerment content: provide guarantee and promote ability;Empowerment type:leader Empowerment,Empowerment project:professional knowledge provider,Empowerment content: expand influence;(3)Empowerment type: cooperation energized, Empowerment project: Third-party enterprise, Empowerment content: data sharing.

Figure 4.the form of DeDao APP value co-creation and enterprise empowerment Source: drawn by the author 


\subsection{Platform - consumer users}

The process of value co-creation between the platform and the consumer users can be divided into the value creation of the platform to the consumer user and the value creation of the consumer user to the platform.

(1)The value creation of the platform for consumers. The platform provides digital audio courses in business, science, art, philosophy, ability and other aspects, e-books, reading comprehension, various ability training camps and other contents, and provides instrumental content such as reading notes and time management equivalence. This part of the content is mainly driven by consumers' demand for knowledge, the psychological factors of knowledge anxiety and the pursuit of profits of the platform itself.The corresponding carrier is the interface push of the platform, as well as the portrait of users and the development of the corresponding learning plan.(2)The value creation of consumer users to the platform.Consumer users can share enterprise profits, platform traffic, platform data analysis sources and user's own reading notes. The content of this part is mainly driven by the enterprise platform value and the user's own interest in the content provided by the platform. The corresponding carrier is the user's subscription behavior, purchase and use records.

(2)There is also a process of enterprise empowerment between the platform and consumer users.

The DeDao app can empower consumers and promote the construction and development of knowledge community in the platform. The platform gives consumers the right to participate in community interaction, and each knowledge product on the app has relevant community functions (learning group and comment area).At the same time, the DeDao app also sets "invite friends to read" and consumers can share their subscribed knowledge products with other friends.Based on the platform social networking and platform sharing functions, consumers can not only exchange their learning experience, but also find like-minded friends.Thus promoted the spread of knowledge.

\subsection{Platform -knowledge provider}

The process of value co creation between platform and knowledge provider can be divided into value creation of platform to knowledge provider and value creation of knowledge provider to platform.

Knowledge providers create value for the platform. As professionals in each sub domain, knowledge providers master the relevant knowledge of the sub domain. They are the principals of subscription courses and the interpreters of listening modules. The expert knowledge providers also bring brand popularity and value guarantee for the brand. The content group of this part is driven by the "knowledge realization" of knowledge providers and the realization of their own value. The corresponding carrier is the link between the platform and the knowledge service provider, which can be online or offline

(2)The value creation of the platform for knowledge providers.The first platform is to cooperate with knowledge providers to polish the content of the corresponding plate, edit the corresponding content and make digital media, and then promote it in combination with the platform data,

Second, they will pay commission to knowledge providers, and some expert knowledge providers can also have corresponding profit sharing. The content of this step is mainly driven by the platform's pursuit of profit.The corresponding carriers are also online or offline.

There is also a process of enterprise empowerment between platform and knowledge provider

Here, the author divides knowledge providers into general knowledge providers and expert knowledge providers.

On the one hand, the DeDao app enables the general knowledge providers to attract the corresponding common knowledge providers. On the one hand, the app provides protection for general knowledge providers. For example, when attracting "Li Xiang", Li Xiang paid a sum of money nearly equal to the angel investment scale in the early stage, which provided a basic guarantee for $\mathrm{Li}$ Xiang's knowledge entrepreneurship.On the other hand, getting app will solve problems for knowledge producers. When knowledge makers produce knowledge products, app will not only send teams to conduct in-depth communication with ordinary knowledge providers to solve problems in content creation, but also provide a series of services, such as office space and recording services, to solve some hardware and technical problems for knowledge producers.

On the other hand, the DeDao app provides leadership empowerment for expert knowledge providers. On the one hand, it helps the knowledge providers of this part to match with the consumers and realize the knowledge quickly. What's more important is to expand the academic and social influence of expert knowledge providers through platform support.

\subsection{Platform-third party enterprise}

The process of value co-creation between the platform and the third party can be divided into the value creation of the platform to the third party enterprise and the value creation of the third party enterprise to the platform.

The value creation of the platform for the third party enterprises. The platform holds the corresponding consumer data and behavior preferences. The platform provides this part of data to third-party enterprises, and puts forward corresponding suggestions, and provides a 
platform for third-party enterprises to display goods and services. This part of the content is mainly driven by the platform profit pursuit and the promotion of the platform's own value.The corresponding carrier is the background user data report.

(2)The value creation of the third-party enterprises for platform.Third party enterprises display their goods and services on the platform, which provides advertising revenue and sales commission of goods and services, and provides payment tools for the platform. The content of this part is mainly driven by the profit pursuit and brand promotion of third-party enterprises, and the carrier is online.

It is mainly the cooperation and empowerment between enterprises, making corresponding marketing plans through data sharing, and producing and selling corresponding derivative products according to the core content of platform knowledge payment.

\section{4. consumer users-knowledge providers}

The process of value co-creation between consumer users and knowledge providers is divided into value creation by knowledge providers for consumer users and value creation by consumer users for knowledge providers.

The value creation of knowledge providers for customer users. Knowledge providers will answer questions raised by some consumers and users in the comment column of the course, and through community discussion, the content of the course may be supplemented accordingly, which is mainly driven by the factors that knowledge providers maintain the course quality and improve the participation of consumers and users. Corresponding carriers are comment reply and private message reply.

(2) The value creation of customer users for knowledge providers. Consumer users will give feedback to courses and participate in community discussions, which makes it possible for knowledge providers to improve courses. This part of the content is mainly driven by consumers' social needs and interest in curriculum issues. The corresponding carriers are comments and community discussions.

\section{5. consumer users-third-party enterprises}

The process of value co-creation between consumer users and third-party enterprises is divided into three parts: value creation by enterprises to consumer users and value creation by consumer users to third-party enterprises.

(1)The value creation of the third-party enterprises for customer users. Third-party enterprises provide consumer enterprises with derivatives associated with the platform itself and the platform content, such as books, electronic consumer goods, tourism consumer goods, gifts, etc., and also provide jobs for some consumer users. This part of the content is mainly driven by the profit pursuit of third-party enterprises and the promotion of their own goods and services brands. The corresponding carriers are platform interface entrance and platform push.

(2)The value creation of customer users for the thirdparty enterprises. Consumers and users mainly provide profits for third-party enterprises. This part of the content is mainly driven by the factors of consumers' sense of brand belonging and the use value of goods and services. The corresponding carriers are platform interface and payment tools.

Synthesizing the whole case discussion of DeDao APP, it is found that DeDao APP, as a knowledge-paid platform, is different from the traditional new business model. The core of this business model focuses on two aspects. First, there is a process of value co-creation between enterprises that get DeDao APP as a knowledgepaid platform and other market entities such as consumer users, knowledge providers and third-party enterprises, and there is also a process of value co-creation between consumer users and knowledge providers and third-party enterprises; Second, enterprises that get DeDao APP as a knowledge -paid platform have a process of "empowering" consumers, knowledge providers and third-party enterprises. The two processes are organically combined and shape their new business model together.

\section{CONCLUSION AND RESEARCH PROSPECT}

This paper attempts to explore the specific practice rules of business model innovation of knowledge-based payment platform enterprises by analyzing the single case system of "DeDao APP" business model innovation practice as the research object. The main conclusions of the study are as follows: (1) There is a process of value co-creation between knowledge-paid platform enterprises and other market players, and between market entities of specific knowledge-paid platform enterprises, and this process is bidirectional; (2) Knowledge-paid platform enterprises have a process of "empower" other market entities, and this process is one-way. There is no enterprise "empower" between market entities except knowledge-paid platform enterprises; (3) The value cocreation of knowledge-paid platform enterprises is organically combined with the process of enterprise's "empowerment", which has no sequence, and the two have jointly shaped its platform value and new business model.

The method of case study itself has certain limitations, and the theory put forward has particularity and complexity, and its universality has yet to be tested. As an exploratory and interpretive approach, this paper should deepen a lot of research in multi-level, multi-angle and multi-method in analyzing and summarizing the business model innovation of knowledge payment platform 
enterprises. There are two aspects in the follow-up research work: (1) Whether the process of value cocreation and enterprise "empowerment" exists in a wider platform economy and what is the relationship between them; (2) What role does value creation and enterprise "empowerment" play in increasing operating income and enhancing user stickiness

\section{REFERENCES}

[1] Fang Jun. Payment: the Rise of Internet Knowledge Economy $[\mathrm{M}]$. Beijing: Machinery Industry Press, 2017.

[2] iResearch. China Online Knowledge Payment Market Research Report [R] .2018.

[3] Mair J,Reischauer G.Capturing the dynamics of the sharing economy :Institutional research on the plural forms and practices of sharing economy organizations $[\mathrm{J}]$ Technological Forecasting \& Social Change , 2017, 125(12) : 11-20

[4] Li Guanggan, Tao Tao. E-commerce Platform Ecology and Platform Governance Policy. Managing the World, 2018(6):120-143.

[5] Lushch R F, Vargo S. Service-Dominant Logic: 520 Research and Comment on Management Cases, 2008,6(1).1-10.

[6] Prahalad C.K.,Ramaswamy V., " Co - creation experiences: The next practice in value creation" , Journal of interactive marketing , v01.18,no.3(2004),pp.5-14.

[7] Vargo S.L.,Lusch R.F., "Evolving to a new dominant logic for marketing” , Journa/of marketing, v01 - 68, no. 1(2004), pp.1-17.

[8] Zhong Zhendong and Tang Shoulian: Research on Value Co-creation Based on Service Leading Logic, Soft Science, No.1, 2014.

[9] Graham, P.Mary Parker Follett-Prophet of Management: ACelebration of Writings from the 1920s [M].boston: Harvard Business Press,1995.

[10] Zhao Jianbo. Management Image Leads Strategic Change: A Case Study of Haier's Win-Win Mode of "One Person, One Oneness" [J]. Journal of Nanjing University (Philosophy, Humanities and science society Science), 2014(4):78-86.

[11] Luo Zhongwei, Li Xianjun, Song Xiang, et al. Evolution of enterprise organizational structure from "empowerment" to "empowerment" - Based on the case study of Handu Yishe [J]. China Industrial Economy, 2017(9):174-192.
[12] Liu Fangnong, Wu Nengquan. Exploring the mystery of Kyocera's "amoeba" operation-a case study based on virtual property rights within enterprises [J]. China Industrial Economics, 2014(2):135-147.

[13] sun Zhongwei. from "individual empowerment" to "collective empowerment" and "individual empowerment": the labor rights of Chinese migrant workers since the 21st century [16] acaroa, puntoni S. customer empowerment in the digital age [j]. journal of advertising research, 2016 (1): 1-8.

[14] Yukse M, Milne GR, Miller EG. Social Media as Complementary Consumption: the Relationship between Consumer Empowerment and Social Interactions in Ex- periential and Informative Contexts [J]. Journal of Consumer Marketing, 2016(2):111-123.

[15] Acar OA, Puntoni S.Customer Empowerment in the Digital Age[J]. Journal of Advertising Research, 2016(1):4-8.

[16] Reflection on the Path of Benefit Protection [J]. Journal of East China University of Science and Technology (Social Science Edition), 2013(2):1020.

[17] Eisenhardt K M, Graebner M E.Theory Building from Cases:Opportunities and Challenges[J].Academy of +Management Journal, 2007,50(1):25-32

[18] Translated by Felista Renault. Wang Yonggui et al. management research methods $[\mathrm{M}]$. Beijing: Tsinghua University publishing house, 2015. 